\title{
Monitoring Besaran Listrik dari Jarak Jauh pada Jaringan Listrik 3 Fasa Berbasis Single Board Computer BCM2835
}

\author{
Ady Kurniawan ${ }^{1)}$, Dikpride Despa ${ }^{2}$, M. Komarudin ${ }^{3)}$ \\ 1,2,3) Jurusan Teknik Elektro Universitas Lampung \\ Jl. Prof. Sumantri Brojonegoro No. 1 Bandar Lampung 35145 \\ adykurniawan18@gmail.com
}

\section{ABSTRAK}

Pada jaringan listrik 3 fasa perlu dilakukan monitoring besaran listrik yang meliputi tegangan (V), arus (A), faktor daya (Cos $\theta)$, daya (W) dan konsumsi energi (kWh). Hal tersebut dilakukan untuk mengetahui perubahan besaran listrik terhadap waktu, sehingga dapat diketahui kualitas pasokan energi listrik pada sistem, dapat diketahui jika terjadi gangguan dan dapat diketahui besar konsumsi energi listrik secara berkala.

Untuk pengukuran tegangan digunakan trafo step-down sebagai sensor tegangan, pengukuran arus digunakan sensor arus ACS712-30A dan pengukuran konsumsi energi digunakan $k W h$ meter merk Thera tipe TEM015-D4250. Sedangkan nilai daya didapat dari perhitungan, dimana daya merupakan hasil bagi antara nilai konsumsi energi terhadap waktu. Ketika nilai tegangan, arus dan daya diketahui maka nilai faktor daya juga dapat dihitung karena nilai daya merupakan hasil kali dari tegangan, arus dan faktor daya. Untuk pemrosesan data pengukuran dan perhitungan dibuat pemograman python dengan menggunakan Single Board Computer BCM2835 atau biasa dikenal dengan sebutan Raspberry Pi.

Hasil penelitian ini menunjukkan bahwa alat ukur tegangan, daya dan faktor daya yang digunakan memiliki tingkat presisi yang sesuai dengan standar IEC No. 13B-23, namun untuk alat ukur arus belum memenuhi standar tetapi masih dapat digunakan karena memiliki selisih pengukuran yang kecil jika dibandingkan dengan hasil pengukuran menggunakan alat ukur yang ada di laboratorium. Dengan menggunakan Raspberry Pi, data hasil monitoring berhasil disimpan pada database dan dapat dilihat dari WEB dalam bentuk grafik.

Kata kunci $\quad$ : Jaringan listrik 3 fasa, sensor tegangan, sensor arus, $k$ Wh meter, Raspberry Pi.

\section{ABSTRACT}

Electric measure on the 3-phase electrical network needs to be monitored which includes voltage (V), current (A), power factor (cos $\theta)$, power $(W)$ and energy consumptions $(k W h)$. In order to knows the changes of electrical quantities over time, so quality of electricity supply in the system can be monitored, it can be seen in case of interruption and can be known energy consumption on a regular basis.

Step-down transformer is used as a voltage sensor for voltage measurment, current measurement used ACS712-30A current sensors and measurement of energy consumption used $k W h$ meter brands TEM015 type Thera-D4250. While the power value obtained from the calculation, where power is the quotient between the energy consumption of the time. When the value of the voltage, current and power are known, the value of the power factor can be calculated as the value of power is the product of voltage, current and power factor. For processing measurement data and calculations made using python programming Single Board Computer BCM2835 or commonly known as Raspberry Pi.

The results showed that the voltage measuring devices, power and power factor used have a level of precision that is in accordance with IEC standard No. 13B-23, but for flow devices not meet the standards yet but it can still be used because it has a small difference in measurements compared with the results of measurements using measuring instruments in the laboratory. By using the Raspberry Pi, the data monitoring records successfully stored in the database and can be viewed on the WEB in the form of graphs.

Keywords: 3 Phase electrical network, voltage sensors, current sensors, $k$ Wh meters, Raspberry Pi. 


\section{PENDAHULUAN}

Energi listrik berperan penting dalam memajukan perekonomian masyarakat, banyak peralatanperalatan yang membutuhkan energi listrik untuk mengoperasikannya, baik dalam skala rumah tangga maupun skala industri. Dengan demikian, kualitas pasokan energi listrik sangat penting untuk diketahui karena kualitas energi listrik dapat mempengaruhi kinerja dan usia pakai dari beban atau peralatan yang digunakaan. Adapun faktor-faktor yang mempengaruhi energi listrik tersebut diantaranya adalah tegangan, arus, dan faktor daya pada sistem.

besarnya konsumsi energi listrik setiap hari, setiap minggu atau setiap bulan juga perlu diketahui guna menentukan langkah-langkah untuk melakukan penghematan dalam mengkonsumsi energi listrik sehingga dapat menekan biaya tagihan listrik dan untuk menjaga ketersediaan energi listrik.

Untuk memenuhi kebutuhan di atas, perlu dibuat sebuah sistem monitoring besaran listrik yang meliputi tegangan, arus, faktor daya, daya dan besar konsumsi energi listrik. Untuk itu akan dibuat sistem monitoring besaran listrik yang dapat merekam data selama monitoring dilakukan dan dapat menampilkan hasil monitoring dari jarak jauh melalui WEB sehingga akan lebih efektif dan efisien. Dalam pembuatan sistem monitoring ini digunakan sebuah $\mathrm{kWh}$ meter digital yang telah banyak dijual dipasaran, hal ini dimaksudkan agar hasil pengukuran lebih akurat karena telah memiliki standarisasi pabrikan. Kemudian untuk mengetahui besar arus dan tegangan digunakan sensor arus dan sensor tegangan, selanjutnya daya dan faktor daya dapat diketahui melalui ketiga peralatan tersebut. Untuk pemrograman digunakan Single Board Computer BCM2835 atau biasa disebut dengan nama Raspberry pi, yaitu sebuah komputer mini yang harganya lebih murah dibandingkan dengan komputer PC (Personal Computer). Dengan menggunakan Raspberry pi, sensor-sensor yang digunakan dapat langsung dihubungkan ke Raspberry pi untuk dilakukan pemograman, hasil pengukuranpun dapat langsung ditampilkan dan direkam pada sebuah database. Raspberry pi juga dapat langsung dihubungkan ke jaringan internet layaknya komputer PC, sehingga monitoring dapat dilakukan dari jarak jauh.

\section{TINJAUAN PUSTAKA}

\subsection{Arus Listrik}

Arus listrik adalah banyaknya muatan yang mengalir pada sebuah penghantar dalam waktu satu detik (coulombs per second) ${ }^{[3]}$ yang diukur dalam satuan ampere (A). Arus listrik dapat dirumuskan dengan persamaan berikut : ${ }^{[3]}$

$$
I=\frac{Q}{t} \ldots \ldots \ldots \ldots \ldots(2-1)
$$

Dimana: $\mathrm{I}=$ Arus listrik dalam satuan ampere

(A)

(C)

$$
\mathrm{Q}=\text { Muatan listrik dalam satuan coulomb }
$$

$\mathrm{t}=$ Waktu dalam satuan detik (s)

\subsection{Tegangan Listrik}

Tegangan listrik adalah besarnya beda energi potensial antara dua buah titik yang diukur dalam satuan volt $(\mathrm{V})$. Tegangan dapat juga diartikan sebagai joule per coulomb. ${ }^{[3]}$ Misalkan sebuah baterai memiliki tegangan sebesar $12,6 \mathrm{~V}$, itu berarti setiap muatan 1 coulomb menyediakan energi 12,6 joule. Jika sebuah lampu dihubungkan ke baterai tersebut maka setiap muatan 1 coulomb yang mengalir melalui lampu akan mengkonversi energi sebesar 12,6 joule menjadi energi panas dan energi cahaya. Dengan demikian rumus tegangan adalah sebagai berikut: ${ }^{[3]}$

$$
\mathrm{V}=\frac{\mathrm{E}}{\mathrm{Q}} \ldots \ldots \ldots \ldots \ldots(2-2)
$$

Dimana : $\mathrm{V}=$ Tegangan dalam satuan volt $(\mathrm{V})$

$\mathrm{E}=$ Energi dalam satuan joule $(\mathrm{J})$

$\mathrm{Q}=$ Muatan dalam satuan coulomb $(\mathrm{C})$

\subsection{Daya Listrik dan Energi Listrik}

Daya listrik adalah banyaknya energi listrik yang mengalir setiap detik atau joule per second ${ }^{33}$ yang diukur dalam satuan watt (W). Daya listrik dirumuskan dengan persamaan berikut : ${ }^{[3]}$ 


$$
\begin{aligned}
& E=P . t \ldots \ldots \ldots \ldots(2-3) \\
& P=\frac{E}{t} \ldots \ldots \ldots \ldots \ldots(2-4)
\end{aligned}
$$

Dimana $: \mathrm{P}=$ Daya dalam satuan watt $(\mathrm{W})$

$\mathrm{E}=$ Energi dalam satuan joule $(\mathrm{J})$

$\mathrm{t}=$ Waktu dalam satuan detik (s)

Energi listrik dapat juga didefinisikan sebagai laju penggunaan daya listrik dikalikan dengan waktu selama waktu tersebut. ${ }^{[2]}$ Satuan SI untuk energi listrik adalah Joule (J), namun dalam kehidupan sehari-hari lebih dikenal dengan kiloWatthour (kWh).

Pada jaringan listrik AC dengan bentuk gelombang sinusoidal dikenal beberapa jenis bentuk daya, diantaranya adalah daya kompleks, daya aktif dan daya reaktif. Perkalian tegangan V dengan arus I* dalam kedua besaran ini dalam bentuk kompleks adalah $\mathrm{VI}^{*}$ yang dinamakan daya kompleks dengan simbol $\mathrm{S}$, dalam satuan Volt Ampere (VA). Daya aktif atau daya nyata dirumuskan dengan $\mathrm{S} \cos \theta$ atau $\mathrm{VI}^{*} \cos \theta$ dengan simbol $\mathrm{P}$, dalam satuan Watt (W). Sedangkan daya reaktif atau daya khayal dirumuskan dengan $\mathrm{S} \sin \theta$ atau $\mathrm{VI}^{*} \sin \theta$ dengan simbol Q, dalam satuan Volt Ampere Reaktif (VAR). ${ }^{[2]}$

Hubungan antara ketiga jenis daya diatas dapat dijelaskan dengan sketsa segitiga daya seperti ditunjukkan pada gambar 2.1.

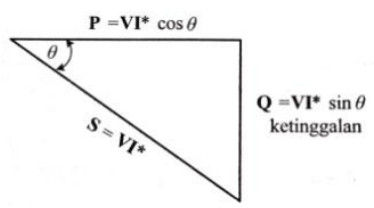

(a) Bersifat induktif.

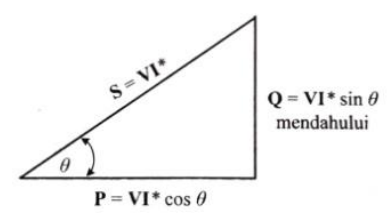

(b) Bersifat kapasitif.

Gambar 2.1 : Segitiga Daya
Komponen-komponen segitiga daya dapat dituliskan sebagai berikut: ${ }^{[2]}$

$\begin{array}{lll}\text { Daya aktif } & : \mathrm{P}=\mathrm{VI}^{*} \cos \theta & (\mathrm{W}) \ldots \ldots \ldots \\ \text { Daya reaktif } & : \mathrm{Q}=\mathrm{VI}^{*} \sin \theta & (\mathrm{VAR}) \ldots \ldots \\ \text { Daya kompleks } & \mathrm{S}=\mathrm{VI}^{*} & (\mathrm{VA}) \ldots \ldots \ldots\end{array}$

Faktor daya $\quad:$ p.f $=\cos \theta$

Sudut fasa $\theta$ muncul akibat adanya selisih fasa antara fasa tegangan dan fasa arus, jika rangkaian bersifat induktif maka fasa arus akan tertinggal dari fasa tegangan, jika rangkaian bersifat kapasitif maka fasa arus akan mendahului fasa tegangan, sedangkan jika rangkaian bersifat resistif maka arus akan sefasa dengan tegangan sehingga sudut fasa $\theta=0$. Dengan adanya sudut fasa $\theta$ maka akan muncul sebuah besaran yang disebut Faktor daya atau power factor (p.f) yang merupakan nilai cosinus dari besar sudut fasa $\theta$. Faktor daya pf sering digunakan sebagai indikator baik atau buruknya pasokan daya pada sebuah sistem. Nilai pf tidak akan lebih besar dari satu (1), jika nilai pf semakin mendekati 1 maka akan semakin baik bagi sistem.

\subsection{Penelitian Terdahulu}

Penelitian-penelitian terdahulu yang menjadi rujukan dalam penelitian ini diantaranya adalah:

a. Rancang Bangun Pencatat Data kWh Meter Jarak Jauh Berbasis Mikrokontroller (Vector Anggit Pratomo, 2012). ${ }^{[6]}$ Penelitian ini menghasilkan sebuah alat untuk menghitung konsumsi energi pada rumah tangga. Alat yang dibuat terdiri dari dua bagian yaitu transmiter dan receiver. Transmiter dipasang pada $\mathrm{kWh}$ meter, sedangkan receiver digunakan untuk melihat hasil perhitungan dari jarak jauh menggunakan wireless. Untuk mendapatkan nilai konsumsi energi hanya digunakan sensor arus, dan untuk mengolah data digunakan mikrokontroller.

b. Rancang Bangun Sistem Monitoring Tegangan, Arus dan Temperatur pada Sistem Pencatu Daya Listrik di Teknik Elektro Berbasis Mikrokontroller Atmega128 (Suryawan Dwi Wahyu, 2012). ${ }^{[9]}$ Penilitian ini menghasilkan alat untuk memonitor tegangan, arus dan suhu pada sistem pencatu daya 3 fasa. Sensor tegangan menggunakan trafo step-down dan sensor arus mengunakan current 
transformer. Data pengukuran diolah pada mikrokontroler untuk ditampilkan pada LCD.

c. Perancangan kWh Meter Digital Menggunakan Sensor Arus ACS712ELC30A (Ihsan Thamrin, 2010). ${ }^{[11]}$ Penelitian ini menghasilkan sebuah $\mathrm{kWh}$ meter digital dengan menggunakan sensor arus ACS71230A, rangkaian pembaca tegangan dan mikrokontroller. Data hasil pengukuran dapat dilihat dari sebuah LCD.

d. Monitoring Pemakaian Energi Listrik Berbasis Mikrokontroller Secara Wireless (Dayita Andyan Rusti, 2011). ${ }^{[8]}$ Penelitian ini menggunakan sensor arus ACS712 dan rangkaian pembagi tegangan untuk sensor tegangan. Dari sensor arus dan sensor tegangan digunakan teknik zerocrossing untuk mendapatkan nilai faktor daya. Dengan demikian nilai konsumsi energi listrik dapat dihitung. Monitoring dapat dilakukan dari sebuah komputer PC dengan jaringan wireless.

e. Rancang Bangun Alat Ukur Arus Menggunakan Transformator Arus Berbasis Mikrokontroler ATmega32 (Dimas Adityawarman, 2014). ${ }^{[1]}$ Penelitian ini menghasilkan alat ukur arus dengan menggunakan current transformer sebagai sensor arus dan mikrokontroler sebagai pengolah data. Hasil pengukuran ditampilkan pada LCD.

f. Energy Monitoring System Berbasis WEB (Novan Zulkarnain, 2013) ${ }^{[15]}$ Penelitian ini menghasilkan alat untuk memonitor pemakaian energi listrik pada sebuah gedung. Data monitoring disimpan pada database dengan aplikasi MySQL, kemudian dibuat grafik dengan pemograman PHP sehingga monitroing dapat dilakukan melalui WEB.

g. Rancang Bangun Sistem Monitoring Bandwidth, Koneksi Listrik dan Temperatur Ruang Berbasis Raspberry Pi pada Gedung Pusat Data Universitas Lampung (Hanang Priambodo, 2014). ${ }^{[7]}$ Penelitian ini menghasilkan alat untuk memonitor bandwidth pada koneksi internet, untuk memonitor koneksi listrik dan suhu ruang. Data hasil monitoring disimpan pada database MySQL dan dapat dilihat dari WEB dalam bentuk grafik.

\section{METODOLOGI PENELITIAN}

\subsection{Blok Diagram Sistem}

Untuk membuat sistem monitoring besaran listrik, alurnya adalah yang pertama dari sumber listrik 3 fasa masuk ke $\mathrm{kWh}$ meter digital, kemudian ke sensor arus dan sensor tegangan, selanjutnya dihubungkan ke beban listrik yang digunakan. Hasil pembacaan $\mathrm{kWh}$ meter dapat langsung dikirim ke Raspberry $\mathrm{Pi}$, sedangkan hasil pembacaan sensor arus dan sensor tegangan harus melalui ADC terlebih dahulu sebelum dikirim ke Raspberry Pi. Selanjutnya Raspberry Pi merupakan tempat membuat program untuk menyimpan hasil monitoring ke dalam database dan menampilkannya ke WEB. Blok diagram sistem ditunjukkan pada gambar 3.2.

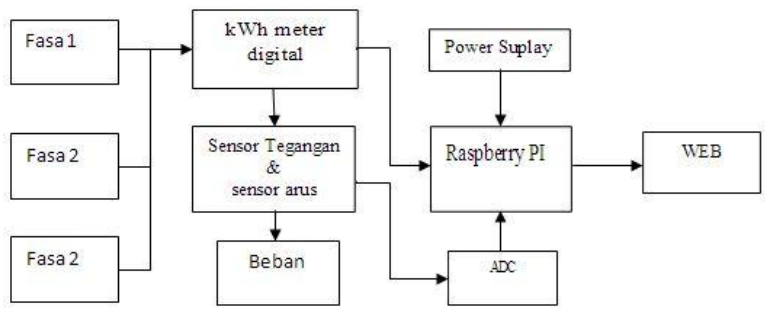

Gambar 3.1 : Blok Diagram Sistem

\subsection{Perancangan Perangkat Keras}

\section{a. Rangkaian Sensor Tegangan}

Dalam perancangan sensor tegangan digunakan transformator step-down untuk menurunkan tegangan dari level tegangan tinggi ke level tegangan rendah. Keluaran trafo masih berupa tegangan AC sehingga dibutuhkan rangkaian pengkondisian sinyal agar didapat tegangan yang aman bagi Raspberry Pi. Rangkaian pengkondisian sinyal ini merupakan rangkaian penyearah dan pembagi tegangan yang berfungsi untuk mendapatkan tegangan DC yang tidak lebih dari 3,3 V agar tegangan dapat dibaca oleh ADC, kemudian dikonversikan ke dalam bentuk sinyal digital untuk diteruskan ke Raspberry Pi. Rangkaian sensor tegangan yang dibuat ditunjukkan pada gambar 3.2. 


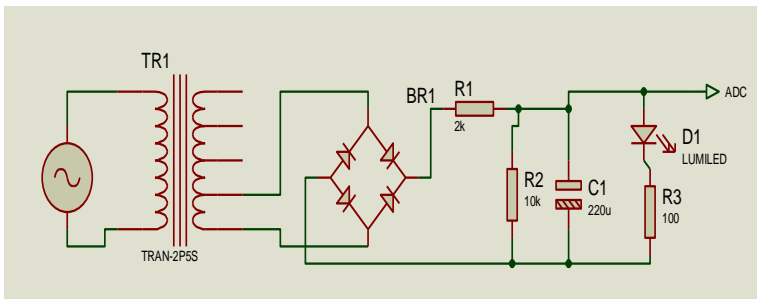

Gambar 3.2 : Rangkaian Sensor Tegangan

\section{b. Rangkaian Sensor Arus}

Sensor arus menggunakan ACS712 30A, sensor ini akan memberikan tegangan output yang linier dengan perubahan arus yang diukur. Sinyal keluaran ACS712 tergantung sinyal masukan, jika arus yang diukur adalah arus AC maka sinyal keluaran merupakan sinyal AC dan jika arus yang diukur adalah arus DC maka sinyal keluaran merupakan sinyal DC. Pada penelitian ini arus yang akan diukur adalah arus AC sehingga perlu ditambahkan dioda penyearah agar didapat sinyal DC pada keluaran sensor sehingga dapat dibaca oleh ADC. Tegangan keluaran sensor maksimal sebesar $5 \mathrm{~V}$ sehingga perlu diturunkan ke level tegangan 3,3V menggunakan rangkaian pembagi tegangan agar tegangan aman bagi Raspberry Pi. Kapasitor digunakan sebagai filter untuk mendapatkan sinyal keluaran yang baik. Rangkaian sensor yang dibuat ditunjukkan pada gambar 3.3.

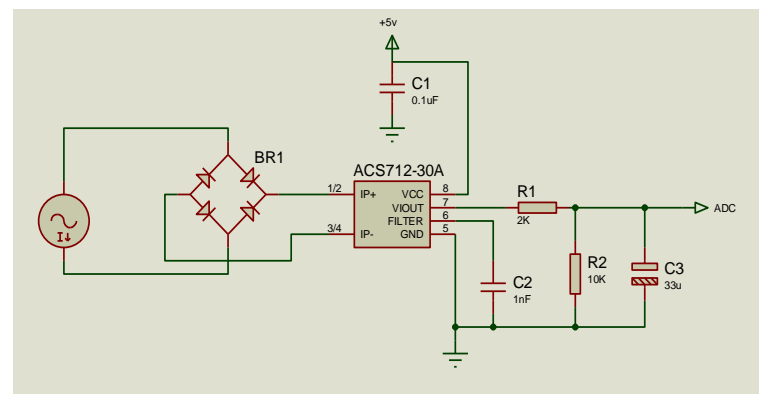

Gambar 3.3 : Rangkaian Sensor Arus.

\section{c. $\mathrm{kWh}$ meter digital}

$\mathrm{kWh}$ meter yang digunakan adalah $\mathrm{kWh}$ meter digital tipe TEM015-D4250. $\mathrm{kWh}$ meter ini digunakan untuk mengukur besar konsumsi energi dan selanjutnya nilai daya dapat di hitung dengan cara membagi nilai $\mathrm{kWh}$ terhadap waktu.

\section{d. Single Board Computer BCM2835}

Single Board Computer BCM2835 (gambar 3.4) atau biasa disebut dengan Raspberry Pi adalah komputer berukuran kartu kredit yang dikembangkan oleh Raspberry Pi Foundation, yang memiliki fungsi yang hampir sama dengan PC kebanyakan. Model PC ini dibagi menjadi dua tipe, yaitu tipe A dan tipe B. Perbedaan keduanya hanya terletak pada memory, jumlah port USB, dan network adaptor.

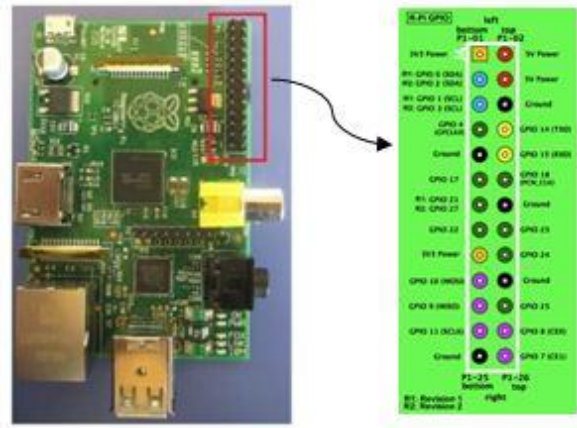

Gambar 3.4 : Raspberry Pi.

Monitoring besaran listrik ini dilakukan pada jaringan listrik 3 fasa, karenanya sensor yang dibutuhkan masing-masing 3 buah. Dari semua sensor tersebut akan didapat nilai tegangan $\mathrm{V}$ (Volt), arus I (Ampere), faktor daya pf $(\operatorname{Cos} \theta)$, daya beban $P$ (Watt), dan konsumsi energi $E$ $(\mathrm{kWh})$ pada masing-masing fasanya. Nilai tegangan, arus dan konsumsi energi di dapat dari pembacaan sensor. Sedangkan nilai factor daya dan daya merupakan hasil perhitungan.Hubungan antara semua sensor dengan Raspberry Pi ditunjukkan pada gambar 3.5.

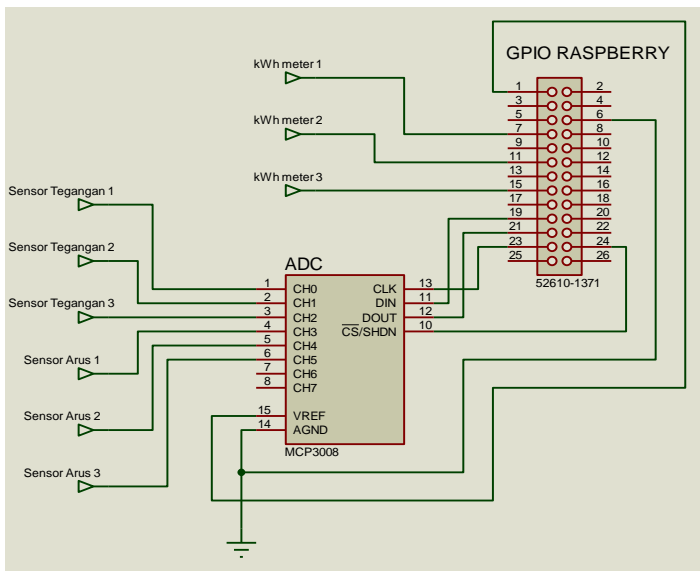

Gambar 3.5 : Koneksi Sensor dengan Raspberry pi. 


\subsection{Pembuatan Program}

Program yang digunakan adalah Pemograman Python dengan menggunakan Raspberry Pi. Program ini meliputi:

- Pembacaan hasil pengukuran sensor,

- Perhitungan untuk mendapatkan besaran yang diinginkan,

- Mencatat hasil pengukuran dalam database dan menampilkan pada WEB

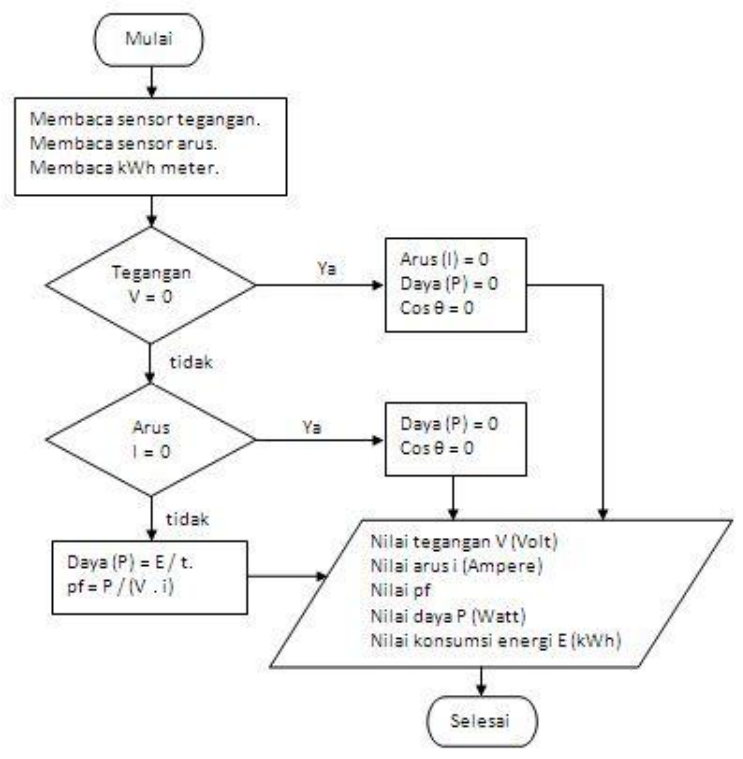

Gambar 3.6 : Diagram alir Program.

Dari gambar 3.6, terlihat keluaran dari sistem yang dibuat adalah nilai Tegangan, Arus, $\operatorname{Cos} \theta$, Daya, dan besar konsumsi energi, masing-masing dapat dijelaskan sebagai berikut :

- Nilai Tegangan didapat dari pembacaan sensor tegangan.

- Nilai Arus didapat dari pembacaan sensor arus ACS712-30A.

- Nilai konsumsi energi didapat dari pembacaan $\mathrm{kWh}$ meter digital.

- Nilai kWh merupakan hasil kali dari daya dengan waktu, sehingga jika nilai $\mathrm{kWh}$ telah diketahui maka nilai daya dapat dihitung menggunakan persamaan (2-3) dan (2-4)

$$
\begin{aligned}
& \mathrm{E}=\mathrm{P} . \mathrm{t} \quad(\mathrm{Wh}) \\
& \mathrm{E}=(\mathrm{P} . \mathrm{t}) / 1000 \quad(\mathrm{kWh}) \\
& \mathrm{P}=\mathrm{E} / \mathrm{t} \\
& \text { Dimana }: \mathrm{P}=\text { Daya }(\mathrm{Watt}) \\
& \mathrm{E}=\text { konsumsi energi }(\mathrm{kWh}) \\
& \mathrm{t}=\text { waktu }(\mathrm{Jam})
\end{aligned}
$$

Kemudian setelah nilai Tegangan, Arus dan Daya diketahui maka faktor daya pf $(\operatorname{Cos} \theta)$ dapat dihitung menggunakan persamaan (2-5) dan (28).

$$
\begin{aligned}
& \mathrm{P}=\mathrm{V} \text {. I } \operatorname{Cos} \theta \\
& \mathrm{Pf}=\mathrm{P} /(\mathrm{V} . \mathrm{I})
\end{aligned}
$$

\section{HASIL DAN PEMBAHASAN}

\subsection{Pengujian Sensor Tegangan}

Pengujian sensor tegangan dilakukan dengan cara mengukur tegangan yang berubah-ubah dengan menggunakan Voltmeter analog, Voltmeter digital dan sensor yang dibuat, kemudian membandingkan hasil pengukuran antar ketiga alat terseut. Nilai tegangan yang berubah-ubah didapat dengan menggunakan Regulator Tegangan. Setelah dilakukan pengujian sensor tegangan didapat data hasil pengujian yang ditampilkan pada tabel 4.1.

Tabel 4.1 : Data Hasil Penguuran Tegangan.

\begin{tabular}{|c|l|l|l|l|l|}
\hline \multirow{2}{*}{ No. } & \multicolumn{5}{|c|}{ Hasil Pengukuran (Volt) } \\
\cline { 2 - 6 } & $\begin{array}{c}\text { Voltmeter } \\
\text { Analog }\end{array}$ & $\begin{array}{c}\text { Voltmeter } \\
\text { Digital }\end{array}$ & Sensor 1 & Sensor 2 & Sensor 3 \\
\hline 1 & 150 & 150,6 & 149,20 & 148,86 & 149,04 \\
\hline 2 & 160 & 161,3 & 160,24 & 160,64 & 161,01 \\
\hline 3 & 170 & 170,4 & 170,21 & 171,06 & 170,70 \\
\hline 4 & 180 & 180,7 & 180,53 & 182,84 & 180,96 \\
\hline 5 & 190 & 190 & 189,43 & 192,35 & 190,08 \\
\hline 6 & 200 & 201 & 199,75 & 202,77 & 199,77 \\
\hline 7 & 210 & 210 & 209,37 & 212,28 & 210,32 \\
\hline 8 & 220 & 221 & 219,33 & 220,89 & 219,44 \\
\hline 9 & 231 & 230 & 229,66 & 231,31 & 230,55 \\
\hline 10 & 240 & 241 & 240,34 & 240,82 & 240,24 \\
\hline
\end{tabular}

\subsection{Pengujian Sensor Arus dan kWh meter.}

Pengujian dilakukan dengan cara memberikan beban listrik yang nilai dayanya berubah-ubah. Kali ini yang akan diuji adalah sensor arus dan $\mathrm{kWh}$ meter, namun sensor tegangan juga digunakan agar nilai Faktor daya dapat dihitung melalui program yang dibuat. Hasil dari pengujian ini merupakan data arus, faktor daya 
dan daya yang masing-masing ditampilkan pada tabel 4.2, tabel 4.3 tabel dan 4.4.

Tabel 4.2 : Data Hasil Pengukuran Arus

\begin{tabular}{|c|l|c|c|c|}
\hline \multirow{2}{*}{ No. } & \multirow{2}{*}{ Beban } & \multicolumn{3}{|c|}{ Hasil Pengukuran Arus (Ampere) } \\
\cline { 3 - 5 } & Sensor & $\begin{array}{c}\text { Alat Ukur } \\
\text { Analog }\end{array}$ & $\begin{array}{c}\text { Alat Ukur } \\
\text { Digital }\end{array}$ \\
\hline 1 & Lampu Pijar & 0,44 & 0,4 & 0,59 \\
\hline 2 & + Lampu Pijar & 0,88 & 0,9 & 0,96 \\
\hline 3 & + Lampu Pijar & 1,32 & 1,35 & 1,37 \\
\hline 4 & + Lampu Pijar & 1,54 & 1,8 & 1,78 \\
\hline 5 & + Kipas Angin & 1,76 & 1,9 & 1,92 \\
\hline 6 & + Kipas Angin & 2,2 & 2,2 & 2,2 \\
\hline 7 & + Heater & 3,74 & 3,7 & 3,7 \\
\hline 8 & + Setrika & 5,28 & 5,2 & 5,28 \\
\hline
\end{tabular}

Tabel 4.3 : Data Hasil Pengukuran Faktor Daya

\begin{tabular}{|c|l|c|c|c|}
\hline \multirow{2}{*}{ No. } & \multirow{2}{*}{ Beban } & \multicolumn{3}{|c|}{ Hasil Pengukuran Faktor Daya (Cos $\boldsymbol{\theta})$} \\
\cline { 3 - 5 } & & Sensor & $\begin{array}{c}\text { Alat Ukur } \\
\text { Analog }\end{array}$ & $\begin{array}{c}\text { Alat Ukur } \\
\text { Digital }\end{array}$ \\
\hline 1 & Lampu Pijar & 0,999 & 0,995 & 0,999 \\
\hline 2 & + Lampu Pijar & 0,993 & 0,995 & 0,999 \\
\hline 3 & + Lampu Pijar & 0,999 & 0,995 & 0,999 \\
\hline 4 & + Lampu Pijar & 0,999 & 0,995 & 0,999 \\
\hline 5 & + Kipas Angin & 0,944 & 0,998 & 0,999 \\
\hline 6 & + Kipas Angin & 0,966 & 0,992 & 0,997 \\
\hline 7 & + Heater & 0,965 & 0,998 & 0,999 \\
\hline 8 & + Setrika & 0,999 & 0,999 & 0,999 \\
\hline
\end{tabular}

Tabel 4.4 : Data Hasil Pengukuran Daya

\begin{tabular}{|c|l|c|c|c|}
\hline \multirow{2}{*}{ No. } & \multirow{2}{*}{ Beban } & \multicolumn{3}{|c|}{ Hasil Pengukuran Daya (Watt) } \\
\cline { 3 - 5 } & & Sensor & $\begin{array}{c}\text { Alat Ukur } \\
\text { Analog }\end{array}$ & $\begin{array}{c}\text { Alat Ukur } \\
\text { Digital }\end{array}$ \\
\hline 1 & Lampu Pijar & 100 & 100 & 95 \\
\hline 2 & + Lampu Pijar & 195,65 & 195 & 189 \\
\hline 3 & + Lampu Pijar & 292,68 & 290 & 283 \\
\hline 4 & + Lampu Pijar & 391,3 & 390 & 376 \\
\hline 5 & + Kipas Angin & 418,6 & 420 & 405 \\
\hline 6 & + Kipas Angin & 473,68 & 475 & 465 \\
\hline 7 & + Heater & 800 & 818 & 797 \\
\hline 8 & + Setrika & 1125 & 1165 & 1145 \\
\hline
\end{tabular}

Dari data hasil pengukuran tegangan, arus, faktor daya daya menunjukkan bahwa hasil pengukuran menggunakan sensor yang dibuat memiliki selisih pengukuran yang kecil jika dibandingkan dengan hasil pengukuran menggunakan alat ukur analog dan alat ukur digital, sehingga sensor yang dibuat cukup layak digunakan untuk sistem monitoring besaran listrik pada panel.

\subsection{Pengujian Sistem.}

Pengujian dilakukan pada panel listrik 3 fasa yang ada di Laboratorium Terpadu Teknik Elektro Unila lantai 2. Langkah pertama adalah memasang Hardware yang dibuat pada panel listrik 3 fasa sebelum masuk ke beban, selanjutnya membuat database sebagai tempat penyimpanan hasil monitoring menggunakan pemograman Python, dan langkah terakhir adalah menampilkan data yang ada dalam Database ke WEB dalam bentuk Grafik. Dalam pengujian ini, Database dibuat menjadi 5 tabel untuk masingmasing pengukuran, yaitu pengukuran Tegangan, Arus, Daya, Faktor Daya dan Konsumsi Energi. Program dibuat agar dapat mengirimkan hasil monitoring setiap 5 detik sekali ke dalam database yang dibuat. Tampilan grafik hasil monitoring pada WEB untuk masing-masing pengukuran ditampilkan pada gambar 4.1, gambar 4.2, gambar 4.3, gambar 4.4 dan gambar 4.5 .

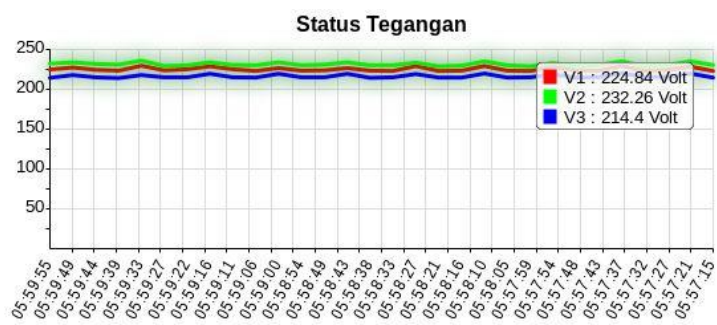

Gambar 4.1 : Grafik Monitoring Tegangan pada WEB

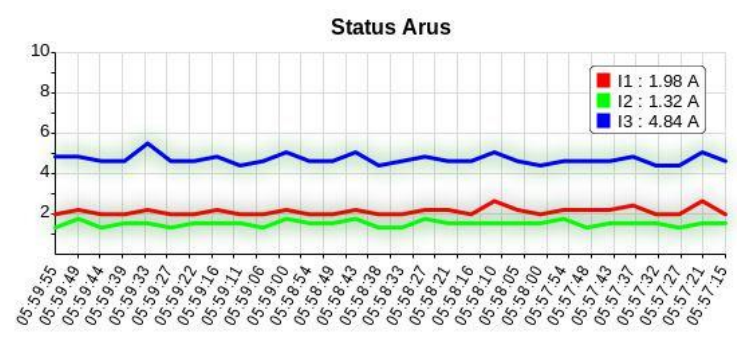

Gambar 4.2 : Grafik Monitoring Arus pada WEB

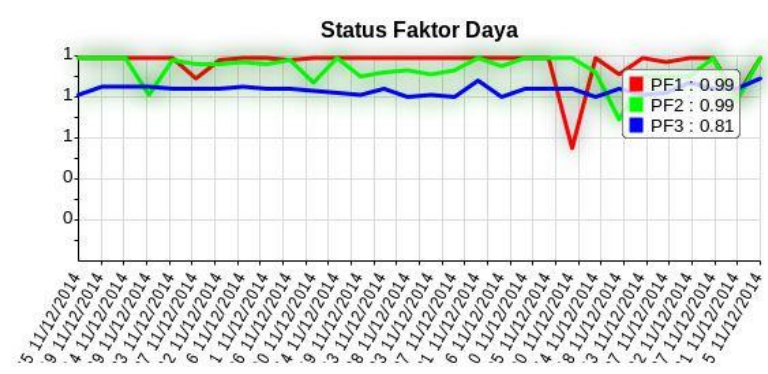

Gambar 4.3 : Grafik Monitoring Faktor Daya 


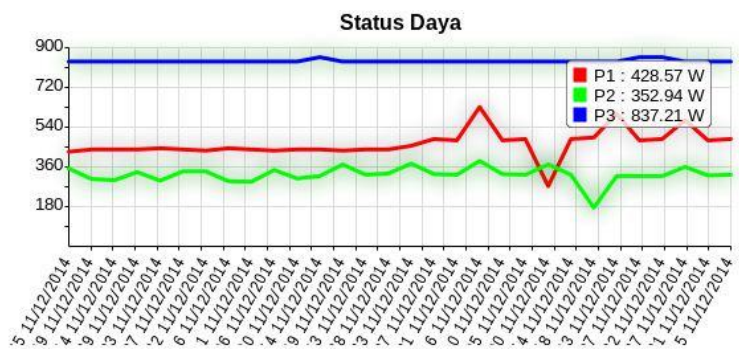

Gambar 4.4 : Grafik Monitoring Daya pada WEB

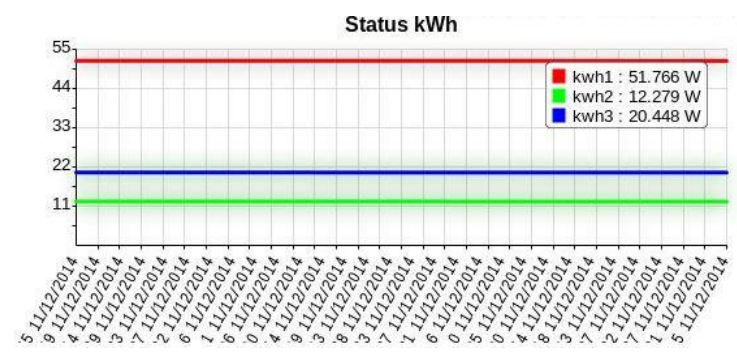

Gambar 4.5 : Grafik Monitoring Konsumsi Energi.

Grafik monitoring yang tampil pada WEB akan terus berubah terhadap waktu sesuai hasil pengukuran sensor yang terpasang pada panel, sehingga perubahan tegangan, arus, faktor daya, daya dan besar konsumsi energi dapat diketahui dengan mudah dari tempat yang jauh melalui jaringan internet.

\section{SIMPULAN DAN SARAN}

\subsection{Simpulan}

Setelah dilakukan analisa data hasil pengujian dari alat yang dibuat, dapat disimpulkan beberapa hal sebagai berikut :

1. Dari data hasil pengujian sensor diketahui rata-rata error untuk pengukuran tegangan mencapai $0,78 \%$, pengukuran arus $12,03 \%$, pengukuran daya $4,84 \%$ dan pengukuran faktor daya $1,87 \%$.

2. Dari error pengukuran menunjukkan bahwa alat ukur tegangan, daya dan faktor daya yang dibuat termasuk alat ukur presisi berdasarkan Standar IEC No. 13B-23, namun untuk alat ukur arus belum memenuhi standar, tetapi masih dapat digunakan pada penelitian ini karena memiliki selisih pengukuran yang kecil jika dibandingkan dengan pengukuran yang menggunakan amperemeter analog dan amperemeter digital.

3. Dari hasil monitoring konsumsi energi listrik selama 24 jam di Laboratorium Terpadu Teknik Elektro lantai 2 pada tanggal 10 Desember 2014 diperoleh data bahwa pada fasa 1 mengkonsumsi energi sebesar $34,4565 \mathrm{kWh}$, fasa 2 sebesar 7,2115 kWh dan fasa 3 sebesar 12,631 kWh. Data tersebut menunjukkan bahwa penggunaan beban pada tiap fasa tidak setimbang.

4. Pada saat pengujian sensor arus tipe ACS712 diketahui bahwa sensor tersebut tidak tahan terhadap arus short circuit, dan ketika mengalami kerusakan akan memutus hubungan antara sumber listrik dan beban.

\subsection{Saran}

Agar sistem monitoring besaran listrik ini dapat dikembangkan lagi, terdapat beberapa saran sebagai berikut :

1. Perlu dirancang sebuah sensor Faktor Daya yang dapat dihubungkan dengan Raspberry pi sehingga tidak perlu menggunakan $\mathrm{kWh}$ meter.

2. Sebaiknya digunakan sensor arus curren transformer jenis cincin, sehingga dalam pemasangan tidak perlu memutus sumber listrik ke beban.

3. Untuk pemograman database dan WEB sebaiknya digunakan komputer bantu yang memiliki spesifikasi yang lebih baik di banding Raspberry Pi, sehingga Raspberry Pi hanya digunakan untuk pemograman pembacaan sensor.

4. Alat yang telah dibuat hanya dapat digunakan untuk monitoring, agar lebih bermanfaat alat dapat dikembangkan dengan menambah rangkaian kontrol jarak jauh.

5. Sebaiknya digunakan mikrokontroler atau sejenisnya untuk mengolah data dari sensor, kemudian data dikirim ke Raspberry Pi melalui jalur serial, sehingga alat dapat digunakan untuk memonitor lebih dari satu panel listrik dengan menambah sensor tanpa menambah Raspberry Pi. 


\section{DAFTAR PUSTAKA}

[1] Adityawarman, Dimas. Rancang Bangun Alat Ukur Arus MenggunakanTransformator Arus Berbasis Mikrokontroler ATmega32. Universitas Lampung, 2014.

[2] Cekdin, Cekmas \& Taufik Barlian. Rangkaian Listrik, Penerbit ANDI, 2013.

[3] Fowler, Richard J. Electricity Principles \& Applications, Penerbit McGraw-Hill, 2008.

[4] Hayt, William H. and Jack E. Kemerly. Rangkaian Listrik, Penerbit Erlangga, 1999.

[5] Malvino, Albert Paul. Prinsip-prinsip Elektronika, Penerbit Salemba Teknika, 2003

[6] Pratomo, Vektor A. Rancang Bangun Pencatan Data kWh meter Jarak Jauh Berbasis Mikrokontroller. Universitas Budi Luhur, 2012.

[7] Priambodo, Hanang. Rancang Bangun Sistem Monitoring Bandwidth, Koneksi Listrik dan Temperatur Ruang Berbasis Raspberry Pi Pada Gedung Pusat Data Universitas Lampung. Universitas Lampung, 2014

[8] Rusti, Dayita A. Monitoring Pemakaian Enegi Listrik Berbasis Mikrokontroler Secara Wireless. Politeknik Elektronika Negeri Surabaya, 2011.

[9] Suryawan, Dwi Wahyu. Rancang Bangun Sistem Monitoring Tegangan, Arus dan Temperatur Pada Sistem Pencatu Daya Listrik Di Teknik Elektro Berbasis Mikrokontroler Atmega 128. Universitas Diponegoro,2012.

[10] Susetyo, Budi. Statistika Untuk Analisis Data Penelitian, Penerbit PT Refika Aditama,2012.

[11] Thamrin, Ihsan. Perancangan $k W h$ Meter Digital Menggunakan Sensor Arus ACS712ELC30A. Universitas Komputer Indonesia, 2010.

[12] Tumanski, S. 2006. Principles of Electrical Measurement, Penerbit Taylor \& Francis Group. 2006.

[13] Waluyanti, Sri. Alat Ukur dan Teknik Pengukuran. Penerbit Direktorat Pembinaan Sekolah Menengah Kejuruan. 2008.

[14] Zuhal. Dasar Teknik Tenaga Listrik dan Elektronika Daya, Penerbit PT Gramedia Pustaka Utama, 1995.

[15] Zulkarnain, Novan. Energy Monitoring System Berbasis Web. Universitas Bina Nusantara, 2013. 